gate dysproteinaemias, and a review by Fred Rosen, one of the foremost workers in immunodeficiencies, on the clinical applications of complement studies. The section on cellular immunology describes lymphocyte transformation and migration tests and how to assay $B$ and $T$ cells in patients. There are also sections dealing with tissue typing, transfusion reactions, new methods used in allergy, and immunodiagnosis of cancer. The section on autoimmune disorders is limited to laboratory methods for haemolytic anaemias, rheumatology, and liver diseases. There was not time in a crash course to discuss all the endocrine autoimmune disorders and many other recent advances.

The essays are readable and not too technical and the references are well into 1974 so the material is reasonably up to date. The book will be popular for departmental and medical school libraries and for clinicians or pathologists who have to prepare lectures or look up a particular topic. It does not contain sufficient detail for the actual practice of all these new branches of immunology which are gradually becoming essential to modern medicine. It might stimulate some young workers to take up immunopathology as a fascinating career in which future opportunities look promising. The price is high by British standards, but this must apply to all books coming from the USA. DEBORAH DONIACH

Clinical Microbiology. How to Start and When to Stop. Edited by Albert Balows. (Pp. ix + 91; illustrated; $£ 10.50$.) Illinois: Charles C. Thomas. 1975.

This hard-backed book is designed to offer guidance to small laboratories on what they should provide by way of service and embodies the proceedings of a seminar held in Chicago in May 1974. After the introductory chapter, of the same title as the handbook, five chapters deal with respiratory cultures, blood culture practices, urine cultures, faecal cultures, and wound and abscess cultures.

The differences in the concept and organization of clinical microbiology in the United States and the United Kingdom are so great that this work is unlikely to help microbiologists in this country. The observation that technical staff 'must have an acceptable education and a modest amount of experience in microbiology' illustrates the gulf that divides practice in the two countries, and the advice not to start at all 'if the laboratory cannot isolate organisms in pure culture and conduct a minimum number of tests to arrive at a presumptive identification of organisms likely to be encountered' gives frightening insight into what may be a major problem in United States practice. So, too, the advice to maintain good rapport with the medical staff scarcely commends itself in a country where clinical microbiologists are the medical staff.

The book serves the purpose for which it was written and, judged from this standard, is lucidly presented and sensible. The authors are to be congratulated on their attempt to improve services through education.

\section{ROSALINDE HURLEY}

Diseases of the Liver and Biliary System, 5th edition. By Sheila Sherlock. (Pp. Xv + 821; illustrated; $f 13 \cdot 50$.) Oxford: Blackwell Scientific Publications. 1975.

This new edition of a classical textbook deals with virtually all that is currently accepted in relation to the aetiology, investigation, diagnosis, and treatment of hepatic disease. It will undoubtedly prove even more successful than its predecessors. Professor Sherlock is a superb clinician, who gives a lucid account of the many aspects of her subject, using the minimum of words. The information contained in a textbook of this size is surprisingly wide and well up-dated. There are four new chapters, including one on hepatic transplantation, and one previous chapter has been expanded into two. There are 1000 new references and 139 new illustrations.

Unfortunately, a biochemist would justifiably raise a number of criticisms. It is the consensus that the $45-$ minute normal for the $5 \mathrm{mg} / \mathrm{kg}$ BSP is $0-6 \%$ and not $0-3 \%$. In health, total serum bilirubin is not infrequently higher than $0.8 \mathrm{mg} / \mathrm{dl}$. $5^{\prime}$-Nucleotidase is not as reliable in the diagnosis of cholestasis as we are given to believe. Paper has largely been replaced by cellulose acetate for electrophoresis of serum proteins. The accounts of urinary excretion of conjugated bilirubin and urobilinogen are somewhat confused. Enzyme induction does not require increased DNA. Humans differ from bacteria in regard to gene control mechanisms. Microsomes are not stimulated by ion-exchange resin but by its effects. Ceruloplasmin is not responsible for the transfer of plasma copper. Mucopoly
saccharides are not glycoproteins. The formulae for the bile acids are incorrect There are, in fact, a number of othef biochemical errors. It is fortunate, how ever, that most, including those mentioned $\overline{\bar{\sigma}}$ do not greatly detract from the clinicaf worthiness of the book.

It is a pity that a superb collection of illustrations of hepatic histopathology continues to be marred by undue reduce tion in size, possibly for reasons of economy.

A. L. LATNER के

Blood Group Topics. Current Topics inj Immunology Series, No. 3. By Barbara E Dodd and Patrick J. Lincoln. (Pp. xii t+ 141 ; illustrated; £5.45.) London: Edwarb Arnold. 1975.

In teaching blood group serology to 울 trainee haematologists it is easy to refer them to the well recognized standard text books on the subject but they cannot be expected to read such books from covero to cover unless they are dedicated to करे specialist life in this particular field. The modern haematologist is more likely too be clinically orientated and less of as leader in technology. He needs to knowo the principles of antigen-antibody react tions and something of the chemistry of immunoglobulins so that he can interpre clinical findings in terms of pathogenesis of disease.

Blood Group Topics is a delightfully concise, relatively easy to read paper-back. volume, half of which is devoted to the anatomy and physiology of blood group antigens and antibodies. The second hals of the book turns to clinical applications starting with problems in finding compatible blood and progressing to the causes and treatment of haemolytic disease in infants and adults.

The authors claim to be addressing themselves to the busy clinician who finds. the ever expanding field of immunologyos impinging on his understanding of disease $\mathrm{N}$ The opening paragraph is a friendly warning to readers not to be daunted if they find the first chapter too foreign; it is suggested they start with a later chaptero and come back to the beginning.

In the reviewer's opinion, this book has? a much wider application and should be recommended to candidates for the MRCO Path examinations in haematology and immunology as it puts blood groupके serology into perspective.

W. J. JENKIN 